\title{
Carcinoma renal metastásico de localización atípica. Revisión de la literatura
}

\author{
D.A. Pérez Fentes, M. Blanco Parra, V. Toucedo Caamaño, J. Lema Grille, \\ A. Cimadevila García, M. Villar Núñez
}

Servicio de Urología. Hospital Clínico Universitario de Santiago de Compostela. Santiago de Compostela.

Actas Urol Esp 2005; 29 (7): 621-630

\section{RESUMEN}

CARCINOMA RENAL METASTÁSICO DE LOCALIZACIÓN ATÍPICA. REVISIÓN DE LA LITERATURA

Objetivo: Revisar en la literatura localizaciones metastásicas atípicas de carcinoma de células renales, su momento de presentación, características clínicas, diagnóstico, tratamiento y pronóstico.

Material y Métodos: Revisión, en la literatura en lengua castellana de los últimos cinco años, de localizaciones atípicas de metástasis de carcinoma de células renales. Búsqueda realizada en la base bibliográfica Medline.

Resultados: En los últimos cinco años se han publicado 15 artículos en lengua castellana sobre metástasis atípicas de carcinoma de células renales. Pacientes de predominio masculino con edad media de 62,3 años. Metástasis en su mayoría metacrónicas diagnosticadas mediante pruebas de imagen con confirmación histológica. Localizaciones principales: intraocular, injerto renal, laríngea, suprarrenal, etmoidal, escrotal, cerebral, peneana, gástrica y pancreática. Tratamiento quirúrgico en lesiones resecables. Paliativo con inmuno-radioterapia en el resto.

Conclusiones: El carcinoma de células renales representa el 3\% de todas las neoplasias malignas del adulto. Metastatiza, por orden de frecuencia, a pulmones, hueso e hígado, pudiendo ser sincrónicas o metacrónicas. El carcinoma de células renales metastásico tiene una amplia variabilidad en cuanto a localización, clínica, momento de presentación, evolución y pronóstico. El abordaje diagnóstico-terapéutico debe ser individualizado, en función de factores pronósticos. El conocimiento de estas localizaciones atípicas en pacientes con antecedentes de carcinoma de células renales influirá en un diagnóstico y tratamiento precoces pudiendo modificar el curso evolutivo de la enfermedad.

Palabras clave: Cáncer renal. Metástasis. Diagnóstico. Tratamiento.

\section{ABSTRACT}

ATYPICAL SITES OF METASTATIC RENAL CARCINOMA. LITERATURE REVIEW

Objective: To review in the literature atypical sites of metastatic renal cell carcinoma, its onset, clinical features, diagnosis, treatment and prognosis.

Methods: To review, using Medline database, atypical sites of metastatic renal cell carcinoma in the last five years Spanish literature.

Results: There have been published 15 spanish articles about atypical metastatic renal cell carcinoma in the last five years. Most patients were male with a mean age of 62,3 years and methacronous metastases. Imaging and pathological diagnosis. Main sites: ocular, renal graft, larynx, suprarenal, brain, penis, gastric and pancreatic. Surgical treatment if the surgeon is able to remove the lesion. Inmunotherapy and radiotherapy in the rest of cases.

Conclusions: Renal cell carcinoma represents about $3 \%$ of all adult malignancy neoplasms. Its metastatic sites, in order of frequency, are lung, bone and liver, whether synchronic or methacronic. Its location, clinical features, onset, evolution and prognosis is very variable. Individualized diagnostic and therapeutic approach, according to prognostic factors. The knowledge of this atypical sites in patients with renal cell carcinoma in the past can lead us to an earlier diagnosis and treatment which could change the evolution of the illness.

Keywords: Renal cancer. Metastasis. Diagnosis. Treatment. 
$\mathrm{E}$ 1 carcinoma de células renales supone el 2-3\% de las neoplasias malignas del adulto. En los últimos años su incidencia ha aumentado, influyendo en ello el desarrollo y empleo sistemático de métodos de diagnóstico por imagen (Ecografia, TC, RMN...) que permiten el diagnóstico precoz en estadios asintomáticos. Sin embargo, y pese a la precocidad diagnóstica, un tercio de estos tumores presentan enfermedad metastásica en el momento del mismo (metástasis sincrónicas) y alrededor de otro tercio la presentarán en el futuro (metástasis metacrónicas) habiéndose descrito casos de aparición más de 20 años después de la nefrectomía.

La presentación clínica del cáncer renal y de su enfermedad metastásica es muy variable. Actualmente la triada clásica de: dolor lumbar, masa palpable y hematuria solamente aparece en un $10 \%$ de los pacientes, siendo el hallazgo clínico aislado más frecuente la hematuria. La gran variabilidad clínica y evolutiva así como la relativa frecuencia de síndromes paraneoplásicos asociados hacen que este tumor sea conocido como el "tumor del internista".

$\mathrm{El}$ carcinoma renal metastatiza, por orden de frecuencia, a pulmón, hueso, hígado, suprarrenales y cerebro. No obstante, no es infrecuente que se localice en otros órganos, lo que definiremos como metástasis de localización atípica, objetivo de nuestra revisión.

Este hecho es debido a la localización anatómica del riñón y su relación con las estructuras vasculares vecinas. Muchos trabajos de esta revisión aportan posibles vías de diseminación hacia estas localizaciones.

En esta revisión discutiremos casos clínicos de enfermedad renal metastásica de localización atípica, analizando su diagnóstico (clínico, pruebas diagnósticas de sospecha y confirmación) y las alternativas terapéuticas actuales.

\section{MATERIAL Y MÉTODOS}

Revisión, en la literatura en lengua castellana de los últimos cinco años, de artículos relativos a localizaciones atípicas de carcinoma de células renales. Utilizando la base de datos Medline, se realiza una búsqueda aplicando los siguientes límites: lengua castellana y artículos (casos clínicos y revisiones) relativos a humanos publicados entre el 1 de Enero de 2000 y el 31 de Diciembre de 2004.
Se revisan 15 artículos publicados en forma de caso clínico con estas características. Se extraen datos de los mismos para agruparlos en función de las siguientes variables: sexo, edad, características del tumor primario, lugar de metástasis, momento de aparición, clínica de presentación, diagnóstico de sospecha, diagnóstico de confirmación, tratamiento y evolución.

Discusión de aspectos diagnóstico-terapéuticos generales y análisis detallado en función de la localización del carcinoma renal metastásico.

\section{RESULTADOS}

Con los criterios de búsqueda anteriormente mencionados se revisan 15 artículos. Las características detalladas de cada caso en cuanto a sexo, edad, características del tumor primario, lugar de metástasis, momento de aparición, clínica de presentación, diagnóstico de sospecha, diagnóstico de confirmación, tratamiento y evolución se recogen en la Tabla I.

Se trata de una serie de 18 pacientes, de predominio masculino (10 varones, 6 mujeres y 2 casos en los que no se especifica el sexo). Edad media de 62,3 años con desviación típica de 12,2 y rango entre 35 y 81 años. La mayoría de los tumores primarios fueron estadios mayores o iguales a T3 o pT3 según la clasificación TNM de la UICC de 1997, habiendo varios casos en los que no se aportan datos para su correcto estadiaje.

En cuanto al momento de aparición de la enfermedad metastásica, la mayoría se presentaron de forma metacrónica, en algunos pacientes en distintos momentos y localizaciones en el curso evolutivo de la enfermedad, siendo la presentación más tardía de la serie a los 10 años de la nefrectomía. Al igual que sucede con el resto de variables, hay publicaciones en las que no se precisa el momento de aparición.

El diagnóstico de sospecha se realizó en casi todos los casos mediante métodos de imagen no invasivos (Ecografía, Rx tórax, TC, RMN) o invasivos (endoscópicos), confirmándose histológicamente en las muestras de biopsia o de exéresis en el caso de cirugía.

La actitud terapéutica fue quirúrgica en los casos en los que se trataba de lesiones resecables, habiendo pacientes en la serie que tuvieron 
Tabla 1

Características de la serie

\begin{tabular}{|c|c|c|c|c|c|c|c|c|c|c|}
\hline Autores & Sexo & Edad & $\begin{array}{l}\text { Características } \\
\text { del tumor } \\
\text { primario }\end{array}$ & $\begin{array}{l}\text { Lugar de } \\
\text { metástasis }\end{array}$ & $\begin{array}{l}\text { Momento de } \\
\text { aparición }\end{array}$ & Clinica & $\begin{array}{l}\text { Diagnóstico de } \\
\text { sospecha }\end{array}$ & $\begin{array}{l}\text { Diagnóstico de } \\
\text { confirmación }\end{array}$ & Tratamiento & Evolución \\
\hline $\begin{array}{l}\text { Herrera, J } \\
\text { et al. }\end{array}$ & Mujer & 67 & $\begin{array}{l}\text { Hipernefroma } \\
\text { izquierdo, pT3N0M0 }\end{array}$ & Cerebral & $\begin{array}{l}\text { Metacrónico } \\
\text { a los } 9 \text { meses }\end{array}$ & $\begin{array}{l}\text { Crisis clónicas } \\
\text { Paresia miembro } \\
\text { inferior derecho }\end{array}$ & TC craneal & AP lesión cerebral & $\begin{array}{l}\text { Craneotomía y exéresis } \\
\text { Radioterapia craneal } \\
\text { externa }\end{array}$ & $\begin{array}{l}\text { Exitus a los } \\
14 \text { meses }\end{array}$ \\
\hline $\begin{array}{l}\text { Quevedo, I } \\
\text { et al. }\end{array}$ & Varón & 54 & $\begin{array}{l}\text { CCR de células } \\
\text { claras derecho, } \\
\text { pT3bNOM0, grado II } \\
\text { de Fuhrman }\end{array}$ & $\begin{array}{l}\text { Cerebral } \\
\text { (Hipofisario) }\end{array}$ & $\begin{array}{l}\text { Metacrónico } \\
\text { a los } 5 \text { años }\end{array}$ & $\begin{array}{l}\text { Apoplejía } \\
\text { hipofisaria }\end{array}$ & TC craneal & AP lesión cerebral & Exéresis quirúrgica & $\begin{array}{l}\text { Enfermedad } \\
\text { estable a los } \\
7 \text { años }\end{array}$ \\
\hline $\begin{array}{l}\text { Gómez, } \\
\text { JA et al. }\end{array}$ & & & $\begin{array}{l}\text { CCR de células } \\
\text { claras izquierdo, } \\
\text { pT3b, grado III de } \\
\text { Fuhrman. }\end{array}$ & Ojo derecho & Sincrónico & $\begin{array}{l}\text { Dolor lumbar } \\
\text { Hematuria } \\
\text { macroscópica } \\
\text { Dolor ocular } \\
\text { Pérdida de } \\
\text { visión }\end{array}$ & $\begin{array}{l}\text { ECO abdominal } \\
\text { RMN abdominal } \\
\text { Fondo de ojo } \\
\text { RMN craneo- } \\
\text { orbitaria }\end{array}$ & AP ojo derecho & $\begin{array}{l}\text { Nefrectomía radical } \\
\text { Enucleación ojo derecho }\end{array}$ & ¿? \\
\hline $\begin{array}{l}\text { Rodriguez, } \\
0 \text { et al. }\end{array}$ & Varón & 45 & $\begin{array}{l}\text { CCR de células } \\
\text { claras derecho, } \\
\text { pT2N0M0 }\end{array}$ & $\begin{array}{l}\text { Pulmón } \\
\text { Ojo derecho }\end{array}$ & $\begin{array}{l}\text { Metacrónico } \\
\text { a los } 6 \text { años y } \\
8 \text { meses } \\
\text { Metacrónico } \\
\text { a los } 7 \text { años }\end{array}$ & $\begin{array}{l}\text { Pérdida de } \\
\text { visión ojo } \\
\text { derecho }\end{array}$ & $\begin{array}{l}\text { TC torácico } \\
\text { RMN } \\
\text { TC craneal }\end{array}$ & $\begin{array}{l}\text { Broncoscopia y } \\
\text { biopsia } \\
\text { AP ojo derecho }\end{array}$ & $\begin{array}{l}\text { Enucleación ocular } \\
\text { Interferón e Interleukina }\end{array}$ & $\begin{array}{l}\text { ¿Metástasis } \\
\text { suprarrenal? }\end{array}$ \\
\hline $\begin{array}{l}\text { Larrosa, F. } \\
\text { et al. }\end{array}$ & Mujer & 65 & $\begin{array}{l}\text { CCR izquierdo con } \\
\text { metástasis única } \\
\text { suprarrenal } \\
\text { contralateral }\end{array}$ & Etmoidal & Sincrónico & $\begin{array}{l}\text { Epistaxis de } \\
\text { repetición } \\
\text { Exoftalmos } \\
\text { Obstrucción } \\
\text { nasal Rinorrea }\end{array}$ & $\begin{array}{l}\text { TC } \\
\text { RMN }\end{array}$ & $\begin{array}{l}\text { Biopsia } \\
\text { endoscópica } \\
\text { endonasal }\end{array}$ & $\begin{array}{l}\text { Exéresis por rinotomía } \\
\text { para-látero-nasal. } \\
\text { Múltiples resecciones } \\
\text { locales por recidiva } \\
\text { sintomática. }\end{array}$ & $\begin{array}{l}\text { Metástasis } \\
\text { cerebrales. } \\
\text { Éxitus al año. }\end{array}$ \\
\hline $\begin{array}{l}\text { Pereira, } \\
\text { JG et al. }\end{array}$ & ¿? & 70 & $\begin{array}{l}\text { Tumoración renal } \\
\text { derecha } \\
\text { No cirugia }\end{array}$ & Nasosinusal & Sincrónico & $\begin{array}{l}\text { Epistaxis de } \\
\text { repetición } \\
\text { Insuficiencia } \\
\text { respiratoria } \\
\text { nasal } \\
\text { Rinorrea }\end{array}$ & $\begin{array}{l}\text { Rinoscopia } \\
\text { TC }\end{array}$ & $\begin{array}{l}\text { AP pieza } \\
\text { quirúrgica }\end{array}$ & $\begin{array}{l}\text { Embolización } \\
\text { Cirugía endoscópica } \\
\text { Inmunoquimioterapia }\end{array}$ & $\begin{array}{l}\text { Éxitus a los } 6 \\
\text { meses }\end{array}$ \\
\hline $\begin{array}{l}\text { Campos, } \\
\text { C et al. }\end{array}$ & ¿? & ¿? & $\begin{array}{l}\text { CCR de células } \\
\text { claras izquierdo, con } \\
\text { afectación } \\
\text { suprarrenal } \\
\text { ipsilateral, pT3a } \\
\text { NxMx }\end{array}$ & $\begin{array}{l}\text { Bronquio } \\
\text { intermediario } \\
\text { derecho }\end{array}$ & $\begin{array}{l}\text { Metacrónico } \\
\text { al año } \\
\text { Metacrónico } \\
\text { a los } 2 \text { años }\end{array}$ & Hemoptisis & $\begin{array}{l}\text { Laringoscopia } \\
\text { directa } \\
\text { TC }\end{array}$ & $\begin{array}{l}\text { AP pieza } \\
\text { quirúrgica } \\
\text { Broncoscopia y } \\
\text { biopsia }\end{array}$ & $\begin{array}{l}\text { Extirpación quirúrgica de } \\
\text { lesión polipidea en } \\
\text { vallécula derecha junto } \\
\text { con vaciamiento } \\
\text { ganglionar ipsilateral }\end{array}$ & ¿? \\
\hline $\begin{array}{l}\text { Suárez, C } \\
\text { et al. }\end{array}$ & Mujer & 61 & $\begin{array}{l}\text { CCR de células } \\
\text { claras izquierdo, } \\
\text { pT3bNOM0, grado } \\
\text { II-III de Fuhrman }\end{array}$ & $\begin{array}{l}\text { Pulmón } \\
\text { Estómago }\end{array}$ & $\begin{array}{l}\text { Metacrónico } \\
\text { a los } 2 \text { años. } \\
\text { Metacrónico } \\
\text { a los } 4 \text { años. }\end{array}$ & $\begin{array}{l}\text { No precisa } \\
\text { Dolor } \\
\text { epigástrico } \\
\text { Astenia } \\
\text { Melenas }\end{array}$ & $\begin{array}{l}\text { No precisa } \\
\text { Panendoscopia } \\
\text { oral } \\
\text { Ecoendoscopia } \\
\text { gástrica }\end{array}$ & $\begin{array}{l}\text { No precisa } \\
\text { Biopsia } \\
\text { endoscópica }\end{array}$ & $\begin{array}{l}\text { Lobectomía superior } \\
\text { derecha } \\
\text { Paliativo (Habia enfermedad } \\
\text { diseminada en el estudio } \\
\text { de extensión) }\end{array}$ & $\begin{array}{l}\text { Enfermedad } \\
\text { estable a los } 6 \\
\text { meses }\end{array}$ \\
\hline $\begin{array}{l}\text { Ruibal, M } \\
\text { et al. }\end{array}$ & Varón & 61 & $\begin{array}{l}\text { CCR de células } \\
\text { claras } \\
\text { izquierdo, pT2N0 }\end{array}$ & Páncreas & $\begin{array}{l}\text { Metacrónico } \\
\text { a los } 5 \text { años }\end{array}$ & Asintomático & TC abdominal & PAAF & $\begin{array}{l}\text { Pancreatectomía parcial } \\
\text { con preservación de } \\
\text { cabeza }\end{array}$ & $\begin{array}{l}\text { Enfermedad } \\
\text { estable a los } \\
10 \text { meses }\end{array}$ \\
\hline \multirow[t]{3}{*}{$\begin{array}{l}\text { Espinoza, R. } \\
\text { et al. }\end{array}$} & Varón & 71 & CCR derecho & Páncreas & $\begin{array}{l}\text { Metacrónico } \\
\text { a los } 10 \text { años }\end{array}$ & Asintomático & TC abdominal & $\begin{array}{l}\text { AP pieza } \\
\text { quirúrgica }\end{array}$ & $\begin{array}{l}\text { Pancreatectomía subtotal } \\
\text { con esplenectomia y } \\
\text { resección parcial de } \\
\text { cabeza de páncreas }\end{array}$ & $\begin{array}{l}\text { Asintomático a } \\
\text { los } 2 \text { años }\end{array}$ \\
\hline & Mujer & 73 & CCR derecho & Páncreas & $\begin{array}{l}\text { Metacrónico } \\
\text { a los } 4 \text { años }\end{array}$ & Asintomática & TC abdominal & $\begin{array}{l}\text { AP pieza } \\
\text { quirúrgica }\end{array}$ & $\begin{array}{l}\text { Pancreatectomia distal y } \\
\text { esplenectomia }\end{array}$ & $\begin{array}{l}\text { Enfermedad } \\
\text { estable a los } \\
10 \text { meses }\end{array}$ \\
\hline & Varón & 81 & CCR izquierdo & $\begin{array}{l}\text { Duodeno } \\
\text { Páncreas }\end{array}$ & $\begin{array}{l}\text { Metacrónico } \\
\text { No precisa } \\
\text { tiempo }\end{array}$ & $\begin{array}{l}\text { Hemorragia } \\
\text { digestiva alta }\end{array}$ & $\begin{array}{l}\text { Endoscopia } \\
\text { digestiva alta } \\
\text { TC abdominal }\end{array}$ & $\begin{array}{l}\text { Biopsia endoscópica } \\
\text { AP pieza quirúrgica }\end{array}$ & $\begin{array}{l}\text { Duodenopancreatectomía } \\
\text { cefálica }\end{array}$ & $\begin{array}{l}\text { Enfermedad } \\
\text { estable a los } \\
2,5 \text { años }\end{array}$ \\
\hline
\end{tabular}


Tabla 1 (CONTINUACIÓN)

\begin{tabular}{|c|c|c|c|c|c|c|c|c|c|c|}
\hline Autores & Sexo & Edad & $\begin{array}{l}\text { Características } \\
\text { del tumor } \\
\text { primario }\end{array}$ & $\begin{array}{l}\text { Lugar de } \\
\text { metástasis }\end{array}$ & $\begin{array}{l}\text { Momento de } \\
\text { aparición }\end{array}$ & Clinica & $\begin{array}{l}\text { Diagnóstico de } \\
\text { sospecha }\end{array}$ & $\begin{array}{l}\text { Diagnóstico de } \\
\text { confirmación }\end{array}$ & Tratamiento & Evolución \\
\hline \multirow{4}{*}{$\begin{array}{l}\text { De Nova, } \\
\text { E et al. }\end{array}$} & & & & $\begin{array}{l}\text { Suprarrenal } \\
\text { Izquierda }\end{array}$ & $\begin{array}{l}\text { Metacrónico } \\
\text { a los } 6 \text { años }\end{array}$ & Asintomática & RMN & $\begin{array}{l}\text { AP suprarrenal } \\
\text { izquierda }\end{array}$ & $\begin{array}{l}\text { laparotomía izquierda y } \\
\text { exéresis suprarrenal } \\
\text { Izquierda }\end{array}$ & \\
\hline & Mujer & 62 & $\begin{array}{l}\text { CCR de células } \\
\text { claras derecho, }\end{array}$ & $\begin{array}{l}\text { Suprarrenal } \\
\text { izquierda }\end{array}$ & $\begin{array}{l}\text { Metacrónico } \\
\text { a los } 3 \text { años }\end{array}$ & Asintomática & $\begin{array}{l}\text { TC abdominal } \\
\text { de control }\end{array}$ & PAAF & $\begin{array}{l}\text { Suprarrenalectomía } \\
\text { izquierda }\end{array}$ & \\
\hline & & & $\begin{array}{l}\text { pT3bN0M0, grado II } \\
\text { de Fuhrman }\end{array}$ & & & & & $\begin{array}{l}\text { AP de suprarrenal } \\
\text { izquierda }\end{array}$ & & ¿? \\
\hline & & & & $\begin{array}{l}\text { Suprarrenal } \\
\text { derecha }\end{array}$ & $\begin{array}{l}\text { Metacrónico } \\
\text { a los } 5 \text { años }\end{array}$ & Asintomática & $\begin{array}{l}\text { TC abdominal } \\
\text { de control }\end{array}$ & $\begin{array}{l}\text { AP de suprarrenal } \\
\text { derecha }\end{array}$ & $\begin{array}{l}\text { Suprarrenalectomía } \\
\text { derecha }\end{array}$ & \\
\hline \multirow[t]{2}{*}{$\begin{array}{l}\text { Calleja, J } \\
\text { et al. }\end{array}$} & Varón & 66 & $\begin{array}{l}\text { CCR de células } \\
\text { claras derecho, }\end{array}$ & & & Asintomático & $\begin{array}{l}\text { Rx tórax de } \\
\text { control }\end{array}$ & No & & Éxitus a los \\
\hline & & & $\begin{array}{l}\text { pT3bN0, grado III de } \\
\text { Fuhrman }\end{array}$ & Escrotal & $\begin{array}{l}\text { Metacrónico } \\
\text { a los } 6 \text { meses }\end{array}$ & $\begin{array}{l}\text { Nódulos } \\
\text { palpables en } \\
\text { raíz del pene }\end{array}$ & $\begin{array}{l}\text { Exploración } \\
\text { fisica } \\
\text { ECO escrotal }\end{array}$ & PAAF & $\begin{array}{l}\text { Radioterapia paliativa } \\
\text { por sindrome de } \\
\text { compresión medular }\end{array}$ & 15 meses. \\
\hline $\begin{array}{l}\text { Herrera, J } \\
\text { et al. }\end{array}$ & Varón & 74 & $\begin{array}{l}\text { Tumoración renal } \\
\text { derecha con trombo } \\
\text { en vena renal } \\
\text { ipsilateral y vena } \\
\text { cava inferior. } \\
\text { No cirugia }\end{array}$ & Pene & Sincrónico & $\begin{array}{l}\text { Hematuria } \\
\text { total } \\
\text { intermitente } \\
\text { Bultoma } \\
\text { indoloro en } \\
\text { pene }\end{array}$ & $\begin{array}{l}\text { TC tóraco- } \\
\text { abdómino- } \\
\text { pélvico }\end{array}$ & $\begin{array}{l}\text { Biopsia fría } \\
\text { nódulo peneano }\end{array}$ & Sintomático & $\begin{array}{l}\text { Éxitus a los } 9 \\
\text { meses. }\end{array}$ \\
\hline $\begin{array}{l}\text { Gómez, I } \\
\text { et al. }\end{array}$ & Varón & 62 & $\begin{array}{l}\text { Tumoración renal } \\
\text { derecha. } \\
\text { No cirugia }\end{array}$ & Injerto renal & $\begin{array}{l}\text { Sincrónico } \\
\text { con riñón } \\
\text { nativo }\end{array}$ & Dolor lumbar & $\begin{array}{l}\text { ECO abdominal } \\
\text { TC abdominal }\end{array}$ & $\begin{array}{l}\text { PAAF injerto } \\
\text { renal }\end{array}$ & $\begin{array}{l}\text { Analgesia } \\
\text { Reducción } \\
\text { inmunosupresión }\end{array}$ & $\begin{array}{l}\text { Éxitus a las } 4 \\
\text { semanas. }\end{array}$ \\
\hline
\end{tabular}

que someterse a varias intervenciones debido a la aparición de enfermedad metastásica en distintas localizaciones en el tiempo. En el resto de pacientes de la serie se optó por inmunoterapia y/o radioterapia en función de las características del lugar de metástasis.

En cuanto a la evolución-pronóstico, es la variable que menos se refleja en los distintos artículos revisados. Se encuentran casos de pronóstico infausto (éxitus al mes) y otros de buena evolución, asintomáticos a los 7 años.

\section{DISCUSIÓN}

El carcinoma de células renales es el tercer tumor urológico en frecuencia después del cáncer de próstata y del cáncer de vejiga y supone el 2$3 \%$ de los tumores malignos del adulto. Alrededor del 30\% de los pacientes presentan metástasis en el momento del diagnóstico o en los primeros seis meses después del mismo (metástasis sincrónicas) y un porcentaje similar las presentarán en el curso evolutivo de la enfermedad (metástasis metacrónicas). Los lugares más frecuentes de metástasis por carcinoma de células renales son: pulmón, hueso, hígado, suprarrenales y cerebro; sin embargo, pueden encontrarse en otros órganos sólidos, como presentamos en esta revisión, debido a la existencia de vías de diseminación alternativas (linfáticas, arteriales y venosas) que permiten su aparición en localizaciones atípicas. 
Si bien el diagnóstico de cáncer renal clásicamente era clínico, su expresión tardía y el desarrollo de los medios de diagnóstico por imagen hacen que cada vez se estén diagnosticando más tumores renales en pacientes asintomáticos de forma incidental, siendo menos frecuente su presentación como dolor lumbar, masa palpable y hematuria. Parece que con un mayor diagnóstico incidental de carcinoma de células renales se modifica la historia natural de la enfermedad, pues un menor número de pacientes presentarán metástasis.

El carcinoma de células renales presenta extensión a dos niveles: local (invasión de glándula suprarrenal por contigüidad, grasa perirrenal, vena renal, vena cava) y a distancia (principalmente a través del sistema venoso, también vía arterial o linfática). Inicialmente está indicada la realización de pruebas de imagen para evaluar la extensión local (TC abdominal o RMN) y, dado que el 30\% debutan con enfermedad metastásica y el pulmón es el principal órgano diana, una radiografía simple de tórax. Ante la aparición de clínica que sugiera otra localización metastásica, estaría indicado realizar nuevas exploraciones de imagen (TC craneal...)

La TC abdominal es la técnica con mejor relación coste-beneficio en la evaluación de la extensión local y la RMN es el método de imagen más preciso y menos invasivo en la evaluación de la existencia y extensión del trombo tumoral. La radiología torácica es la exploración de imagen con mejor relación coste-beneficio para la estadificación pulmonar. Actualmente está en discusión la aplicación de la tomografía de emisión de positrones (PET) en la estadificación de pacientes con cáncer renal ${ }^{1}$.

$\mathrm{El}$ carcinoma renal metastásico tiene una evolución variable. En la literatura se recogen desde remisiones espontáneas post-nefrectomía hasta evoluciones rápidamente fatales. Están descritas metástasis hasta más de 20 años después de la nefrectomía. Es, por tanto, extremadamente importante tener en cuenta este antecedente pues estos pacientes pueden presentar metástasis en cualquier momento y en cualquier localización, con clínicas variables. Ante la sospecha de enfermedad renal metastásica es obligado el estudio mediante las pruebas de imagen necesarias y el diagnóstico de confirmación en función de la localización. No obstante, pese a estos casos de aparición tardía, no está justificado el seguimiento en pacientes asintomáticos con nefrectomía previa por cáncer de riñón más allá de los 5 años para tumores pT1 y pT2 y más allá de 10 años para tumores pT3 y pT4. ${ }^{2}$

Actualmente la actitud terapéutica en estos pacientes es individualizada en función de sus características clínicas y factores pronóstico. En la literatura hay publicados numerosos estudios sobre factores predictivos de mala evolución en el carcinoma renal: pérdida de peso, grado nuclear elevado, aumento de velocidad de sedimentación globular, hipercalcemia, aneuploidía del DNA, anemia, hipoalbuminemia, aumento de LDH, niveles de interleucina 10 elevados (en discusión), aumento de fosfatasa alcalina... Sin embargo, los factores de buen pronóstico en los que coinciden la mayoría de las series son: buen estado general del paciente, intervalo libre entre nefrectomía y aparición de metástasis superior a 1-2 años (según las series), número de metástasis y localización de las mismas y nefrectomía previa. ${ }^{3}$ Nosotros, al igual que otros grupos consideramos que es más importante que las metástasis sean resecables en su totalidad que el número de las mismas, aunque sí parece influir su órgano afectado (pulmón, mejor pronóstico). En nuestra revisión parece que los pacientes que fueron candidatos a cirugía presentan un mejor pronóstico que aquellos sometidos a tratamiento paliativo con inmuno-radioterapia.

El cáncer renal es un tumor quimiorresistente, radiorresistente y hormonorresistente. Las opciones terapéuticas actuales en el carcinoma renal metastásico son:

- Inmunoterapia (con interferón alfa, interleucina 2 , interferón alfa + interleucina 2 , o combinaciones de estos agentes con quimioterápicos como el 5-fluoracilo). La mayoría de los autores recomiendan la nefrectomía previa al tratamiento inmunoterápico, si bien la indicación debe individualizarse, pues la nefrectomía añade morbilidad a estos pacientes.

- Radioterapia sobre localizaciones metastásicas, con finalidad paliativa (en hueso y sistema nervioso central) 
- Cirugía: la exéresis quirúrgica estaría indicada ante lesiones resecables en su totalidad y en pacientes con buen estado general. La indicación más aceptada es la resección de metástasis pulmonares, estando descrita también la cirugía de masas residuales tras tratamiento sistémico ${ }^{4}$.

A continuación, describiremos cada una de las localizaciones atípicas encontradas en esta revisión, analizando aspectos diagnósticos y terapéuticos de forma individualizada.

\section{Metástasis cerebral}

$\mathrm{El}$ tumor que con mayor frecuencia metastatiza a cerebro es el de pulmón, seguido del melanoma, cáncer de mama e intestino. Las metástasis cerebrales de cáncer de riñón son poco frecuentes (3,9$13,2 \%)$ y de muy mal pronóstico. Se localizan preferentemente en los hemisferios y suelen ser únicas. Clínicamente los pacientes suelen presentar algún tipo de focalidad neurológica, crisis convulsivas, cefaleas por hipertensión intracraneal... El diagnóstico de sospecha se realiza en pacientes sintomáticos mediante TC craneal, confirmándose mediante biopsia. No está, por tanto, indicada su realización en la estadificación de los pacientes sin síntomas relacionados con el sistema nervioso central. Herrera et al. recalcan en su artículo que no existe un criterio unánime en cuanto al tratamiento de estas lesiones. Proponen la exéresis quirúrgica con radioterapia del lecho tumoral para metástasis solitaria resecable y presentan la opinión de otros autores de combinar cirugia e inmunoterapia ${ }^{5}$.

En el artículo de Quevedo et al. se destaca la escasez de casos publicados de metástasis hipofisarias de carcinoma de células renales desde que Eick en 1985 publicase el primero. Presentan un caso de apoplejía hipofisaria solventado exclusivamente con cirugia hipofisaria de urgencia con excelentes resultados, confirmándose histológicamente la existencia de metástasis hipofisaria de carcinoma renal. Los autores destacan la importancia de la inmunohistoquímica (Citoqueratina $\mathrm{AE} 1, \mathrm{AE} 3 \mathrm{y}$ Vimentina positiva) en el diagnóstico diferencial de estas lesiones dado que histológicamente las células hipofisarias pueden presentar la apariencia de células claras debido a acúmulos de lípidos y glucógeno y que radiológicamente son imposibles de diferenciar de adenomas hipofisarios ${ }^{6}$.

\section{Metástasis ocular}

Las metástasis uveales son los tumores malignos intraoculares más frecuentes y su origen más común es la mama. Las metástasis oculares de carcinoma de células renales son muy poco frecuentes, pudiendo presentarse de forma sincrónica o metacrónica. Gómez et al. encontraron publicados seis casos a nivel coroideo, tres en iris y uno en glándula lacrimal, aportando un nuevo caso de localización coroidea a la literatura.

Pueden ser diagnosticadas de forma casual tras un examen oftalmológico rutinario o debutar de forma sintomática (dolor ocular, pérdida de visión...); en dicho caso debe realizarse un examen de fondo de ojo y métodos de diagnóstico por imagen (TC o RMN). Sobre su tratamiento, Alonso et al. recomiendan tratamientos locales para tumores de pequeño tamaño (menos de $5 \mathrm{~mm}$ ) localizados fuera de la mácula: braquiterapia, radioterapia o termoterapia transpupilar. Otros autores recomiendan una actitud conservadora con inmunoterapia (interferón alfa, interleucina 2 o ambos) siempre que no exista dolor ocular persistente o glaucoma secundario. Se ha publicado una supervivencia del $31 \%$ a los tres años en pacientes seleccionados tratados con inmunoterapia. En los casos publicados por ambos grupos la actitud fue quirúrgica (enucleación del globo ocular) debido a que el paciente presentaba dolor ocular y pérdida progresiva de visión $n^{7,8}$.

\section{Metástasis etmoidal}

De los tumores que metastatizan a la cavidad nasal y los senos paranasales el carcinoma de células renales es el más frecuente, seguido a distancia por los tumores primitivos de pulmón, mama y seminoma. La localización más frecuente es en el seno maxilar, seguida del seno etmoidal, frontal, cavidad nasal y esfenoides, en orden decreciente. Se presenta como epistaxis, masa nasal, obstrucción nasal y rinorrea purulenta, deformidad facial, dolor y clínica oftalmológica. Están descritas dos vías de diseminación: a través de la vena cava y a través del plexo venoso paravertebral de Batson.

La TC es el método de imagen de elección en el diagnóstico y estudio de extensión de la lesión metastásica. La RMN presenta mayor sensibilidad en la diferenciación de la lesión tumoral y es 
especialmente útil para evaluar masa residual post-radioterapia. La anatomía patológica de las muestras obtenidas por biopsia endoscópica constituye el diagnóstico definitivo. La biopsia debe ser muy cuidadosa por la elevada tendencia de estas lesiones al sangrado.

Aunque clásicamente el carcinoma de células renales es un tumor radiorresistente, está publicada su efectividad en el tratamiento de la enfermedad metastásica. Los pacientes con buen estado general y con una única lesión metastásica resecable deben ser tratados agresivamente: exéresis quirúrgica asociada a radioterapia. En caso de enfermedad metastásica múltiple o no resecable totalmente, el papel de la cirugía es controvertido: existen protocolos de cirugía citorreductora asociada a radio e inmuno-quimioterapia sin excesivo éxito. El pronóstico de estas lesiones suele ser malo: está publicada una supervivencia menor del $10 \%$ a los cuatro años ${ }^{9,10}$.

\section{Metástasis laringea}

La enfermedad metastásica en laringe es una entidad poco frecuente $(0,09-0,4 \%)$, siendo los tumores primarios más frecuentes melanoma, riñón y colon. Dentro de la localización laringea, la región supraglótica es la más afectada debido a su mayor red linfática. La diseminación del cáncer renal hacia laringe puede entenderse por dos mecanismos: hematógeno (a través del plexo de Batson o a través de vena cava hacia cavidades derechas para llegar a laringe mediante la arteria tiroidea inferior y la arteria laríngea) o linfático. Clínicamente se presentan como disfonía, disfagia o hemoptisis (debido a que son lesiones intensamente vascularizadas). Diagnóstico de sospecha con métodos de imagen que requiere confirmación histológica. Campos et al. describen brevemente la actitud terapéutica ante este tipo de afectación metastásica, que sigue los criterios generales para otras localizaciones: quirúrgico ante lesiones resecables y paliativo con inmunoterapia o radioterapia ante lesiones irresecables y/o pacientes con mal estado general ${ }^{11}$.

\section{Metástasis gástrica}

Las metástasis gástricas tienen una incidencia baja, entre el 0,2 y el 0,7\%, siendo sus focos primarios más frecuentes mama, pulmón y mela- noma. La enfermedad metastásica gástrica secundaria a carcinoma de células renales es una entidad rara, con únicamente 11 casos publicados en la literatura. Se presentan como dolor abdominal inespecífico y/o hemorragia digestiva alta o baja y suelen tratarse de tumores metacrónicos. El diagnóstico definitivo se realiza mediante biopsia endoscópica de la lesión, que suele tener un aspecto sobreelevado en su centro con ulceración en el vértice, con forma de "volcán”, de localización submucosa.

Suárez et al. describen varias teorías sobre la diseminación del cáncer renal hacia estómago. Localizaciones gástricas múltiples se explicarian mediante las vías clásicas de diseminación hematógena y linfática. Las metástasis de localización única seguirían rutas de diseminación no habituales: hematógena retrógrada a través de las venas lumbares, que conectan con la vena gástrica izquierda (propuesta por los autores como vía de diseminación para tumores renales derechos) y linfática mediante el conducto torácico, que normalmente drena en la vena subclavia izquierda pero en la mitad de los casos puede hacerlo a la vena ázigos o hacia venas lumbares (propuesto como vía de diseminación para tumores renales izquierdos, dada su localización).

En general los autores proponen tratamiento quirúrgico radical para metástasis únicas (en pacientes con buen estado general), reservando tratamientos paliativos (embolización de la arteria esplénica, electrocoagulación endoscópica, resección endoscópica) para el resto de casos. Reconocen también el beneficio del tratamiento adyuvante con inmunoterapia en enfermedad renal metastásica ${ }^{12}$.

\section{Metástasis pancreática}

Las metástasis suponen el 2-3\% de tumores pancreáticos, siendo sus focos primarios más frecuentes pulmón, colon, mama y cerebro. La enfermedad metastásica en páncreas por cáncer renal es poco frecuente (se han publicado incidencias que oscilan entre el 1 y el 2,8\%) y suele presentarse de forma sincrónica, aunque se han descrito casos hasta 27 años después de la nefrectomía. Espinoza et al. publican 3 casos de metástasis metacrónicas a los 4 y 10 años de la nefrectomía, no precisando el momento del diag- 
nóstico en el tercero. La mayor crítica a este trabajo se debe, en nuestra opinión, a que no aporta datos relativos al estadio del tumor renal, lo que impide un análisis de factores de riesgo para enfermedad metastásica en un futuro. Por su parte, Ruibal et al. presentan un caso diagnosticado a los 5 años de nefrectomía por un carcinoma de células renales estadio pT2NO.

Suelen presentarse de forma asintomática (aunque hay casos descritos de hemorragia digestiva alta) y ser diagnosticadas en los estudios de control. Los métodos de imagen habituales (TC, RMN) no permiten realizar un diagnóstico diferencial adecuado y algunos autores señalan la utilidad de la ecografía endoscópica. En el artículo de Espinoza et al. destacan la utilidad de la TC helicoidal para el diagnóstico diferencial de estas lesiones; según ellos en fases precoces de la tomografia, tras la administración de contraste intravenoso, se apreciarían lesiones hipervasculares en el parénquima pancreático en el caso de tumor metastásico renal, que difiere del adenocarcinoma primario de páncreas, típicamente hipovascular. Estos hallazgos no son patognomónicos. Ruibal et al. y otros autores realizan el diagnóstico de confirmación mediante PAAF guiada por TC, aunque señalan los riesgos e inconvenientes de esta técnica. El resto de los autores realizan este diagnóstico tras la exéresis quirúrgica de la pieza. En este tipo de metástasis también se sigue la tendencia general de realizar resecciones quirúrgicas completas con intención curativa ante metástasis únicas resecables, dejando (en el caso del páncreas) suficiente tejido para sostener la función endocrina, sin necesidad de una disección linfática radical. En cuanto a su pronóstico, es mejor que el de los tumores primarios de páncreas. Según Espinoza et al. su sobrevida media puede ampliarse con la inmunoterapia adyuvante ${ }^{13,14}$.

\section{Metástasis suprarrenal}

Los tumores primarios que con mayor frecuencia metastatizan en la glándula suprarrenal son mama, pulmón y melanoma. Las metástasis suprarrenales por carcinoma de células renales pueden ser sincrónicas o metacrónicas y presentarse de forma unilateral (ipsilateral o contralateral al tumor primario) o bilateral.
En la revisión de De Nova et al. ${ }^{15}$ se define la afectación metastásica de la glándula suprarrenal como una enfermedad sistémica con resultado ominoso. La vía de diseminación más frecuente es vascular, debido a la intensa irrigación suprarrenal, incluso en tumores renales de polo superior en los que la lógica nos lleva a pensar en una diseminación por contigüidad. Se ha publicado una intensa correlación entre enfermedad suprarrenal metastásica bilateral y afectación ganglionar así como entre metástasis suprarrenal contralateral y afectación de vena renal o vena cava, coincidiendo este hecho con uno de los casos presentados por De Nova et al.

Este grupo recomienda la nefrectomía radical ampliada para metástasis ipsilateral diagnosticada pre o intraoperatoriamente, proponiendo actitudes más complejas para enfermedad metastásica bilateral. Sobre las masas adrenales detectadas en el seguimiento del paciente nefrectomizado por cáncer renal, proponen la PAAF Eco-dirigida o TC-dirigida para confirmar el diagnóstico de metástasis. En su artículo únicamente se realiza PAAF (punción aspiración con aguja fina) a un paciente con metástasis suprarrenal contralateral metacrónica debido a que en el resto de los casos la historia del paciente traducía una alta sospecha de enfermedad metastásica. Los autores realizan una revisión del tratamiento sistémico con inmunoterapia de la que se extrae que la combinación de interleucina 2 con 5-Fluoracilo es la que mayor tasa de respuestas obtiene. Asimismo discuten las indicaciones para realizar nefrectomía citorreductora en el carcinoma renal metastático.

\section{Metástasis escrotal}

Desde que Bandler en 1964 publicase la primera metástasis testicular de cáncer renal hasta la actualidad, únicamente hay descritos en la literatura 21 casos de metástasis testiculares. Calleja et al. detallan las vías de diseminación hematógena tumoral: arterial (previo establecimiento de metástasis pulmonares, a través de cavidades cardíacas izquierdas) y venosa (mediante sistemas venosos colaterales hacia la vena espermática en casos de vena renal trombosada o mediante el plexo venoso de Batson); existiendo también la posibilidad de diseminación linfática. 
Al igual que en otras localizaciones metastásicas, el pronóstico es pobre y la actitud es quirúrgica únicamente cuando las metástasis son resecables, con leve mejoría en la supervivencia (29$35 \%$ a los 5 años) ${ }^{16}$.

\section{Metástasis peneana}

La enfermedad metastásica en pene es una entidad rara, habitualmente procedente de órganos como la vejiga, próstata, colon, recto y riñón. Suelen presentarse de forma sincrónica, en el contexto de enfermedad diseminada a otros lugares. Herrera et al. detallan las posibles vías de diseminación a pene desde riñón: embolización arterial, venosa (desde la vena renal a la vena espermática para llegar al plexo profundo del pene) y linfática. Suelen presentarse como nódulo indoloro, tumefacción, dolor, priapismo o disuria. Su diagnóstico definitivo es anatomopatológico. En cuanto a su tratamiento, los autores proponen la exéresis local (valorando diversas técnicas) ante masa peneana única y extirpable o ante cuadros de dolor severo y/o obstrucción uretral. El pronóstico de estos enfermos es malo, el caso publicado falleció a los 9 meses $^{17}$.

\section{Metástasis en injerto renal}

La mayor incidencia de neoplasias en la población trasplantada es debida, entre otros factores, a la inmunosupresión crónica. La enfermedad neoplásica en el trasplantado puede tener tres orígenes: transmisión inadvertida o accidental desde el donante, recurrencia de neoplasias tratadas pretrasplante en el receptor o neoplasias de aparición de novo post-trasplante.

Tras el trasplante renal aumenta la incidencia de neoplasias habituales en la población general (colon, mama, pulmón, próstata...) así como la de otras menos prevalentes. La incidencia media de tumor en la población trasplantada es del $6 \%$, siendo los tumores cutáneos los más frecuentes (carcinoma de células escamosas más que el carcinoma basocelular), seguido de las enfermedades linfoproliferativas y del sarcoma de Kaposi.

En cuanto al carcinoma renal, el riesgo es de 10 a 100 veces superior en los trasplantados que en la población general. Según la revisión de Gómez et al. ${ }^{18}$ esta incidencia en nuestro medio sería de $5,9 \%$. Son factores de riesgo la ingesta previa de analgésicos, historia previa de carcinoma renal y la enfermedad quística renal adquirida, que se analiza en profundidad en el artículo de Gómez et al. Según estos autores, y coincidiendo con la opinión general actual, el desarrollo de carcinoma de células renales a partir de enfermedad quística renal adquirida en pacientes en hemodiálisis es consecuencia de la insuficiencia renal terminal y no secundario al tiempo en hemodiálisis.

En el injerto renal se han descrito ocasionales tumores benignos y tumores malignos, principalmente linfomas. El diagnóstico de sospecha de los mismos se realiza mediante TC, confirmándose con PAAF guiada radiológicamente. Estos autores no aportan datos acerca del tratamiento, quizá debido a que su caso publicado fue éxitus a las tres semanas del diagnóstico debido a que presentaba enfermedad metastásica diseminada.

Hasta el momento actual el artículo de Gómez et al. es el primero en lengua castellana que describe una metástasis en injerto renal procedente de un tumor sólido y el primero en la literatura global que describe una metástasis de carcinoma de células renales sobre injerto. Nurmi et al. publicaron el primero en lengua inglesa, siendo su origen un carcinoma vesical.

\section{Metástasis óseas}

El carcinoma de células renales tiene en el hueso uno de sus principales órganos de metástasis, siendo en su mayoría de características líticas y de afectación axial. El artículo de Ruiz et al. recalca la utilidad de la gammagrafía ósea para el diagnóstico de estas lesiones en pacientes con cáncer renal, aportando un caso a la literatura. Ruiz et al. concluyen que estaría indicada la gammagrafía ósea ante pacientes sintomáticos (dolor nocturno que aumenta con la inmovilidad) o con aumento de la fosfatasa alcalina sérica. Según su artículo, la radiología ósea normal no excluye la existencia de metástasis, dato que apoya su caso clínico. Además, algunos autores defienden el diagnóstico precoz de enfermedad ósea metastásica con gammagrafia frente a radiología convencional. En este artículo se incluye también la crítica de otros estudios sobre la utilidad de la fosfatasa alcalina como marcador en la detección de dichas metástasis ${ }^{19}$. 


\section{REFERENCIAS}

1. Herranz Amo F, Verdú Tartajo F, Bielsa Carrillo A. Estudio de extensión en el adenocarcinoma renal. En Herranz Amo F, editor. Tumores de riñón. Madrid, Ediciones Doyma. 2001;123-135.

2. Mickisch G, Carballido J, Hellsten S, Schulze H, Mensink H. Guidelines on renal cell cancer. Update February 2002. Disponible en http://www.uroweb.org.

3. Herranz Amo F, Diez Cordero JM, García Burgos J. Factores pronósticos en el adenocarcinoma de riñón. En Herranz Amo F, editor. Tumores de riñón. Madrid, Ediciones Doyma. 2001;137-148.

4. Arranz Arija JA, González Beca R, López de Ceballos MH, Muñóz Sánchez MM. Tratamiento de la enfermedad metastásica en el adenocarcinoma de riñón. En Herranz Amo F, editor. Tumores de riñón. Madrid, Ediciones Doyma. 2001;213-230.

5. Herrera Puerto J, Soler Fernández J, Asuar Aydillo S, Dominguez Bravo C, Cabezudo Alzar J. Metástasis cerebral solitaria de un carcinoma de células renales. Actas Urol Esp 2003;27(6):468-470.

6. Quevedo I, Rodríguez JA, Rosenberg H, Mery J. Apoplejía en metástasis hipofisaria de carcinoma de células renales. Caso clínico con siete años de seguimiento. Rev Med Chil 2000;128(9):1015-1018.

7. Gómez Pascual JA, Martínez Martín MS, Bonilla Parrilla R, Irigoyen Díaz J, Del Rosal Samaniego JM, Ramos Titos J et al. Carcinoma renal metastático intraocular. Ceguera unilateral progresiva como forma de presentación. Actas Urol Esp 2004;28(3):324-326.

8. Rodríguez Faba O, Martínez Gómez F, Parra Muntaner L, Martín Benito JL, García Rodríguez J, Jalón Monzón A et al. Carcinoma de células renales con metástasis pulmonar y ocular tardías. Arch Esp Urol 2004;57(5):545-547.

9. Larrosa F, Aguilar F, Traserra J. Metástasis etmoidal de adenocarcinoma renal. Acta Otorrinolaring Esp 2000;51(1): 76-79.

10. Pereira Arias JG, Ullarte Jaime V, Valcarcel Martín F, Onaniel Pérez VJ, Gutiérrez Díez R, Ateca Díaz-Obregón R et al. Epistaxis como primera manifestación de un adenocarcinoma renal diseminado. Actas Urol Esp 2002;6(5): 361-365.

11. Campos Álvarez C, Hernández González JI, Gracia Chapullé A, Duo Buendía MA, Lobo Fernández J, Suárez González JA. Metástasis endobronquiales y laríngeas. Una forma poco habitual de diseminación del hipernefroma. Arch Esp Urol 2000;53(8):734-736.
12. Suárez Fonseca C, Carballido Rodríguez J, González Lama Y, Sola Galarza I, Rodríguez Reina G, Salas Antón C. Metástasis gástrica de un adenocarcinoma renal. Hipótesis patogénica y revisión de la literatura. Actas Urol Esp 2004;28(6):472-476.

13. Ruibal Moldes M, Quintana De la Rosa JL, Fariña Pérez LA, Tardáguila F, Ortíz Rey JA, Zungri Telo E. Metástasis pancreática tardía por carcinoma renal. Actas Urol Esp 2001;25(2):122-124.

14. Espinoza R, Rossi R, Rossi R, Rosenberg H. Metástasis pancreática metacrónica de un carcinoma de células renales. 3 nuevos casos. Rev Med Chil 2001;129(1):86-90.

15. De Nova Sánchez E, Prieto Chaparro L, Galán Llopis JA, Lloréns Martínez F, Fernández Puentes C, Menéndez López $\mathrm{V}$, et al. Enfermedad metastásica de larga evolución en el adenocarcinoma renal. Afectación suprarrenal. Arch Esp Urol 2000; 53(4): 377-382.

16. Calleja Escudero J, Pascual Samaniego M, Martín Blanco S, De Castro Olmedo C, Gonzalo V, Fernández del Busto E. Metástasis intraescrotal de un carcinoma renal. Actas Urol Esp 2004; 8(4):311-313.

17. Herrera Puerto J, Herrera Flores J, López Elzaurdia C, Cermeño Giles F, Pierna Manzano J, Isusquiza Garro I et al. Metástasis peneana de un carcinoma de células renales. Actas Urol Esp 2002;26(8):589-591.

18. Gómez García I, Burgos Revilla FJ, Sanz Mayayo E, Conde Someso S, Quicios Dorado C, Pascual J et al. Metástasis en injerto renal de adenocarcinoma renal primario. Actas Urol Esp 2004;28(6):458-461.

19. Ruiz Hernández G, Ferrer Albiach C, Balaguer Martínez JV, Romero de Ávila C, Castillo Pallarés FJ. Metástasis óseas secundarias a carcinoma renal diagnosticadas mediante gammagrafía ósea. Actas Urol Esp 2001;25(9):679682 .

Dr. D.A. Pérez Fentes

Servicio de Urología

Hospital Clínico Universitario de Santiago de

Compostela.

Travesía Choupana s/n.

15706. Santiago de Compostela.

E- Mail: danielfentes@yahoo.es

(Trabajo recibido el 30 mayo de 2005) 